\title{
Research on Design and Operation Method of Dewater and Filled System for Cushion Pool of High Dams Taking the project of BHT hydropower plant in China as an example
}

\author{
Fang Jie $^{1, a}$, Cao Chunjian ${ }^{1}$, Li Shengbing ${ }^{1}$ \\ ${ }^{1}$ Power China Huadong Engineering Corporation Limited, Hangzhou Zhejiang, 311122
}

\begin{abstract}
Dam is set in large hydropower station. Cushion pool is built behind the dam for the flood discharge and energy dissipation of the reservoir. Operation of flood discharge and energy dissipation for some time, Cushion pool is dewatering and structure safety of which is study, then cushion pool is filled. Temporary dewater and filled system is used by previous engineer, but is arranged and controlled hard. Based on need of the cushion pool dewatering and filling, for an example of Baihetan hydropower station, necessity and feasibility are study. Then a permanent dewatering and filling system is designed for cushion pool. Design principle and arrange method are described. Many technical difficulties are study and resolved such as effect of valley deformation on the control system of dewatering and filling, demand of dewatering and filling device parameter, performance quota formulate based on large water level amplitude, protective measures in the working condition of much silt on the downstream and humidity in the equipment room of the seconddam and project of dewater drainage outlet under the water. By gravity drainage and filling based on water level difference and pump drainage, much electric energy is saved and personnel operating environment and working conditions are improved.
\end{abstract}

\section{1 preface}

Cushion pool is an energy dissipation protection building behind high drop arch dam, which can prevent erosion damage of dam foundation and protect the safety and stability of dam. Usually, when the arch dam is in flood discharge operation, The bottom structure of the water cushion pool may be eroded by the current, so it is necessary to carry out regular pumping maintenance on the cushion pool. At present, many hydropower stations have been built in China, such as Xiluodu ${ }^{[1]},{ }^{[2]},{ }^{[3]}$, Ertan ${ }^{[4]},{ }^{[5]},{ }^{[6]}$, Wudongde ${ }^{[7]},{ }^{[8]}$, Jinping $\mathrm{I}^{[9]},{ }^{[10]}$, [11], etc., a temporary dewatering and filling system was used to repair the water cushion pool which is dewatered and empty.

The cushion pool behind the Xiluodu Hydropower Station's dam is $300 \mathrm{~m}$ in length, with a maximum width of $228 \mathrm{~m}$, a bottom width of $60 \mathrm{~m}$ and a depth of $46 \mathrm{~m}$,After the flood period, it is necessary to inspect and repair the scour of the bottom plate of the cushion pool, and the water inside the cushion pool needs to be pumped and drained before repairing ${ }^{[2]}{ }^{[3]}$. The pumping and emptying of cushion pool is considered as a once-in-20-year flood, and the pure pumping and draining time of the pump is 20 days. Five pumping ships or pontoons are arranged in the coverage area of the cable machine, and two pumps are installed on each pumping ship, The hoses of the pumps are used for pumping and draining in the early stage; As the water level drops, two DN400 $\times 8 \mathrm{~mm}$ steel pipes are respectively arranged on the side slopes of $386 \mathrm{~m} \sim 340 \mathrm{~m}$ of the left and right bank cushion pool which is covered by the cable machine as pumping and drainage pipelines. Later, a pumping ship is used to draw near the second-dam downstream, and DN250mm hose is used for pumping and drainage. According to the planned configuration and layout of pumping device, the requirements of pumping water in cushion pool were fulfilled on schedule. Subsequent construction can be carried out smoothly. From the pumping and drainage method of Xiluodu cushion pool, the pumping device and power cables need to be temporarily set up, At the same time, pontoons are used in cushion pool with a water depth of $46 \mathrm{~m}$, which is extremely inconvenient and has high safety risks, so it is urgent to set up more convenient facilities to replace them.

The cushion pool behind the Goupitan Hydropower Station's dam ${ }^{[12]}$, [13] [14] has a total length of $331.89 \mathrm{~m}$, a bottom width of $66 \sim 70 \mathrm{~m}$, and a complex ladder-shaped cross section. When the cushion pool is overhauled, A single-stage double suction water centrifugal pump and a submersible sewage pump should be provided by the proprietor, and the overhaul company shall organize the drainage of the cushion pool by themselves.

The cushion pool behind the Jinping I Hydropower Station's dam [9], [10] [11] has a total length of $386.50 \mathrm{~m}$, a bottom width of $45 \mathrm{~m}$ and a top width of $112 \mathrm{~m}$, and its cross section is of complex ladder type. The mid-open single stage double suction centrifugal pump, cam pump,

aE-mail: fang_j@ecidi.com 
vacuum pump and submersible sewage pump are purchased by the proprietor for the maintenance and the drainage of the cushion pool, but they were not installed. After the flood period of the first practical year of the cushion pool, the cushion pool will be drained and checked, and then the water level of the downstream reservoir will be raised for reverse filling through the top of the second-dam.

In order to inspect and maintain the bottom of the cushion pool of Ertan Hydropower Station, it is proposed to add $4 \times 220 \mathrm{~kW}$ pump to drain the inspection section ${ }^{[5]}$, and the $6.3 / 0.4 \mathrm{kV}$ substation has been configured and optimized accordingly.

Laxiwa Hydropower Station's cushion pool ${ }^{[18][19]}$ have a total length of $290 \mathrm{~m}$ behind the dam, with a trapezium section from the downstream of the arch dam to $0+055.40 \mathrm{~m}$ below the dam; $0+055.40 \mathrm{~m}$ below the dam $0+240.0 \mathrm{~m}$ below the dam is a counter-arch cushion pool with equal width layout; Xiaowan Hydropower Station's cushion pool ${ }^{[18][19]}$ have a total length of $218.27 \mathrm{~m}$ and a minimum bottom width of $70 \mathrm{~m}$ behind the dam, temporary pumps are used for water pumping and drainage of the water cushion pool.

In summary, temporary water pump drainage is mostly adopted in the dewater and filled of large-scale hydropower station cushion pool, while the water filling is realized by recharging when the water level in the downstream of the second-dam rises. The following problems exist when the temporary pumping mode is adopted: (1) the system construction workload is heavy and the procedures are cumbersome; Manual operation is required in the whole process, which is inconvenient to operate and maintain; The drainage system is inefficient; Device and power supply are mostly outdoors, which may bring potential safety hazards to workers. With the development of technology, higher and higher requirements are proposed for the efficiency of dewatering and filling in cushion pool, including improving the working environment of maintenance personnel, reducing the large amount of construction work of drainage equipment and facilities, and reducing the number of

maintenance personnel. The original temporary drainage mode can't meet the needs of engineering management and maintenance, so it is urgent to set up a set of safe, reliable, simple and convenient cushion pool dewatering and filling system to solve a lot of auxiliary work brought by engineering maintenance management.

Based on the above-mentioned research on the dewatering and filling system of cushion pool of large hydropower station, combined with the structural type and operation needs of cushion pool of high dam hydropower station, a convenient and fast dewatering and filling system of cushion pool is tried to set up, which is combined with the gravity-drainge dewatering and filling system for joint operation. It mainly includes rational allocation and arrangement of main pumping and drainage device, power transformation and distribution equipment and lifting equipment for pumping and drainage in cushion pool; The water inlet and water inlet pipes of the pumping and drainage system are set with different levels, The gravity-drainge dewatering and filling valve are set at a higher position, the gravity-drainge dewatering and filling pipe with the main pumping and drainage pipe are combined, and it will be arranged at the level above the downstream riverbed and along the slope, which can avoid the influence of siltation on the dewatering and filling system of the cushion pool at the upstream and downstream of the second-dam to the greatest extent and ensure the smooth flow of system pipelines and device; The gravity-drainge dewatering and filling valve is arranged in the covered way on one side of the cushion pool. By using the slope of the cushion pool and the bottom plate, the impact of high-speed water flow on the bottom plate when the cushion pool is filled with water can be avoided, which plays a better role in energy dissipation, thus the anti-blocking are greatly improved, anti-moisture and anti-valley extrusion deformation ability of the dewater and filled system of the cushion pool.

\section{2 project overview}

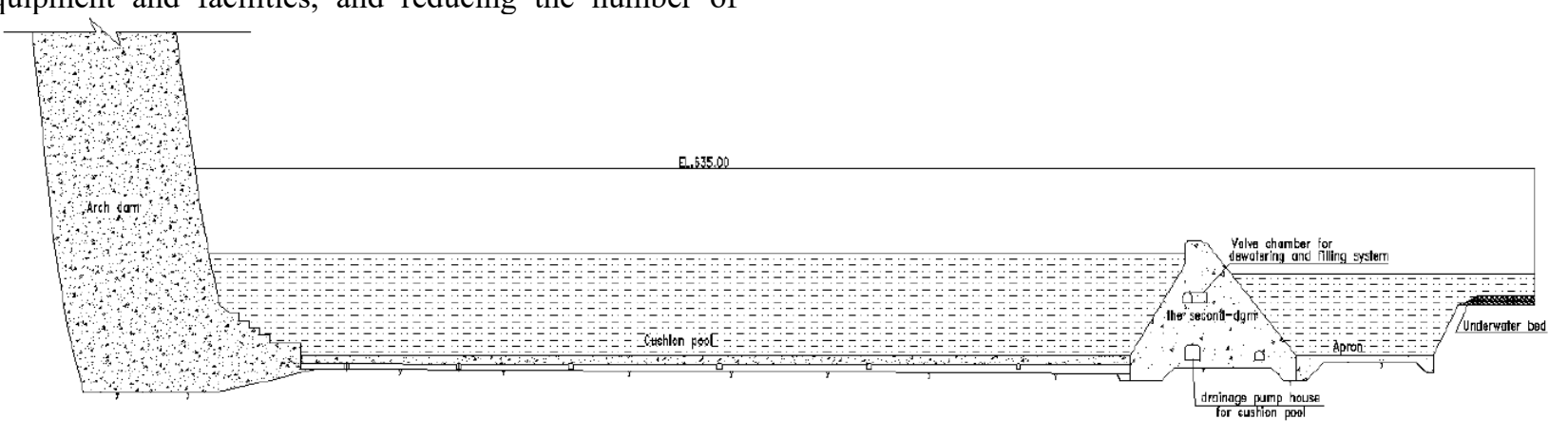

Fig.1 Layout of Energy Dissipation Facilities of High Dam

Baihetan Hydropower Station is located in the lower reaches of Jinsha River at the junction of ningnan county, Sichuan Province and Qiaojia County, Yunnan Province, with an installed capacity of $16000 \mathrm{MW}$, which is the second largest hydropower station in China after the Three Gorges Hydropower Station ${ }^{[20]}$. The power station hub is composed of double arch dam, tunnel spillway on the left bank, and underground water diversion and power generation system on the left and right banks. The maximum dam height of arch dam is $289 \mathrm{~m}$; ; The cushion pool is located behind the dam, with a length of about $360 \mathrm{~m}$, a top level of $635 \mathrm{~m}$ and a top width of $210 \mathrm{~m}$. The second-dam is an overflow dam with bidirectional water retaining, gravity dam type is adopted, with the top of the dam elevation of $606 \mathrm{~m}$, dam height of $51 \mathrm{~m}$, dam width of $8 \mathrm{~m}$ and dam length of $173 \mathrm{~m}$. 


\section{3 design of dewater and filled system for cushion pool}

\section{1 system operating conditions}

The river water quality conditions, the structural layout of the second-dam, the downstream river bed conditions, the upstream and downstream operation water level conditions, the deformation conditions of the river valleys on both sides and the maintenance needs of cushion pool are mainly considered in the operation conditions of dewatering and filling system of cushion pool.

(1) River water quality, when the dam discharges water, a large amount of silt is carried by the water flow. At the same time, there are debris such as rolling stones for upstream flood discharge and uncleaned woven bags at the inlet and drainage pipe mouth. In the process of recharging water, the silt in the downstream river channel may also flow into the pipeline of the dewatering and filling system and the cushion pool, which may cause great hidden danger to the safe operation of the pump, and at the same time may cause siltation of the pumping and drainage pipes and the gravity-drainage pipes, thus affecting the normal operation of the dewatering and filling system of the cushion pool.

(2) The combined working condition of upstream and downstream water levels, the water level range in the cushion pool and downstream river course and the running head range of the pump should be considered in the design of the water dewatering and filling pipeline system. After the recharge water are set up, the pump will initially run at zero head, resulting in overload of the pump motor. After the cushion pool drained, the confluence water at the bottom of the cushion pool is discharged by the pump to the downstream. The fall between the top of the seconddam and the bottom of the cushion pool is large, and the downstream water level varies greatly. Therefore, it is necessary to select a suitable pump to run.

(3) The deformation condition of the valley, certain displacement will also be produced by the second-dam structure behind the cushion pool under the influence of the valley width deformation, and its influence should be considered in the embedding manner of the pump pipeline and the open installation of the exposed pipeline.

(4) Pipelines, the environment of running, maintenance and device, and the scouring effect of high-speed water flow on the cushion pool and the huge noise generated in the pipeline should be solved by the pipeline layout; drainage outlets are submerged in water for a long time, it should be considered to set up underwater maintenance facilities or conditions at the drainage outlets.

(5) Because the bottom of the cushion pool is relatively low, the water recharge in the cushion pool can be completed after the overhaul.

\section{2 main system design}

(1) Study on gravity water dewatering and filling system

The selection of pipe diameter and setting level of operating valves in gravity water dewatering and filling system is the key research, and the selection of pipe diameter is related to the filling water level of cushion pool and the setting level of valves in gravity water dewatering and filling system.

(2) Study on the selection of main parameters of pumps

The maintenance of cushion pool is carried out in the dry season of the river. At this time, the water level of the river channel is low. In order not to affect the power generation of the power station, the highest water level required by the drainage system device and pipeline layout is determined according to the downstream full tail water level $\mathrm{H}_{\max }$, and the lowest operating water level is determined according to the bottom level $\mathrm{H}_{\min }$ of cushion pool, which is included in the pipeline head loss $\mathrm{H}_{\mathrm{f}}$, the maximum operating head of the pump is expressed as follows.

$$
\mathrm{H}_{\mathrm{p}}=\mathrm{H}_{\max }-\mathrm{H}_{\min }-\mathrm{H}_{\mathrm{f}}
$$

The capacity of the dewatering and filling system should not only meet the drainage planning time requirements of cushion pool, but also consider the structural safety impact of water level decline rate of cushion pool. The relationship curve between water level and capacity of cushion pool of Baihetan hydropower station is shown in Figure 2 as an example, The water level $\mathrm{H}$ of cushion pool and water capacity $\mathrm{V}$ in the pool can be expressed as follows.

$$
\mathrm{H}=\alpha \times \mathrm{V}+\beta
$$

The relationship between the capacity $\mathrm{Q}$ of drainage system and the capacity $\mathrm{V}$ of water in pool can be expressed as follows.

$$
\mathrm{V}=\mathrm{Q} \times \mathrm{T}
$$

The relationship between drainage system capacity Q, pool water capacity $\mathrm{T}$ and drainage water level $\mathrm{H}$ can be expressed as follows.

$$
\mathrm{H}=\alpha \times \mathrm{Q} \times \mathrm{T}+\beta
$$

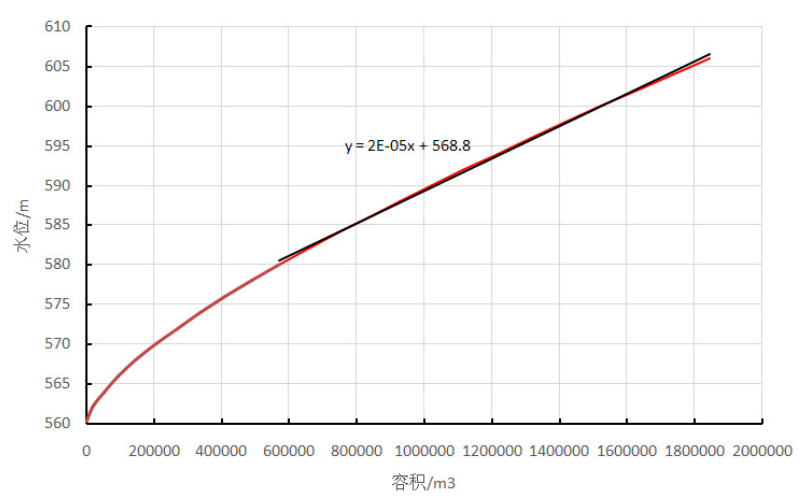

Fig.2 Relationship curve between water level and storage capacity of cushion pool

\section{(3) System composition}

Two parts are consisted of dewatering and filling system of the cushion pool of Baihetan hydropower station, namely, dewater and filled system and the gravity charging and drainage system, as shown in Figure 3 . The horizontal double-suction centrifugal pump are adopted in dewatering and filling system, which is mainly used to 
discharge the dropsy in the cushion pool and the leakage of dam body during the maintenance of the cushion pool. The system is equipped with five large pumps with rated flow of $750 \mathrm{~m}^{3} / \mathrm{h}$ and rated lift of $40 \mathrm{~m}$ and two small pumps with rated flow of $160 \mathrm{~m}^{3} / \mathrm{h}$ and rated lift of $45 \mathrm{~m}$. Two DN500 gravity drainage pipes are set in the gravity water dewatering and filling system. When the cushion pool is overhauled, firstly, the dropsy in the cushion pool is drained to the second-dam behind by gravity flow from the gravity dewatering and filling pipelines, until the water level in the cushion pool is close to the water level behind the second-dam, and then the overhaul and drainage pump works at the same time. When dropsy in the cushion pool is completely drained, two small pumps are used to drain dropsy in the cushion pool. After the maintenance of the cushion pool is completed, the downstream tail water is back filled into the cushion pool by using the gravity dewatering and filling pipelines. Pressure gauges and electromagnetic flowmeters are set at the inlet and outlet of the maintenance drainage pump for operation control and flow monitoring of the maintenance drainage pump.

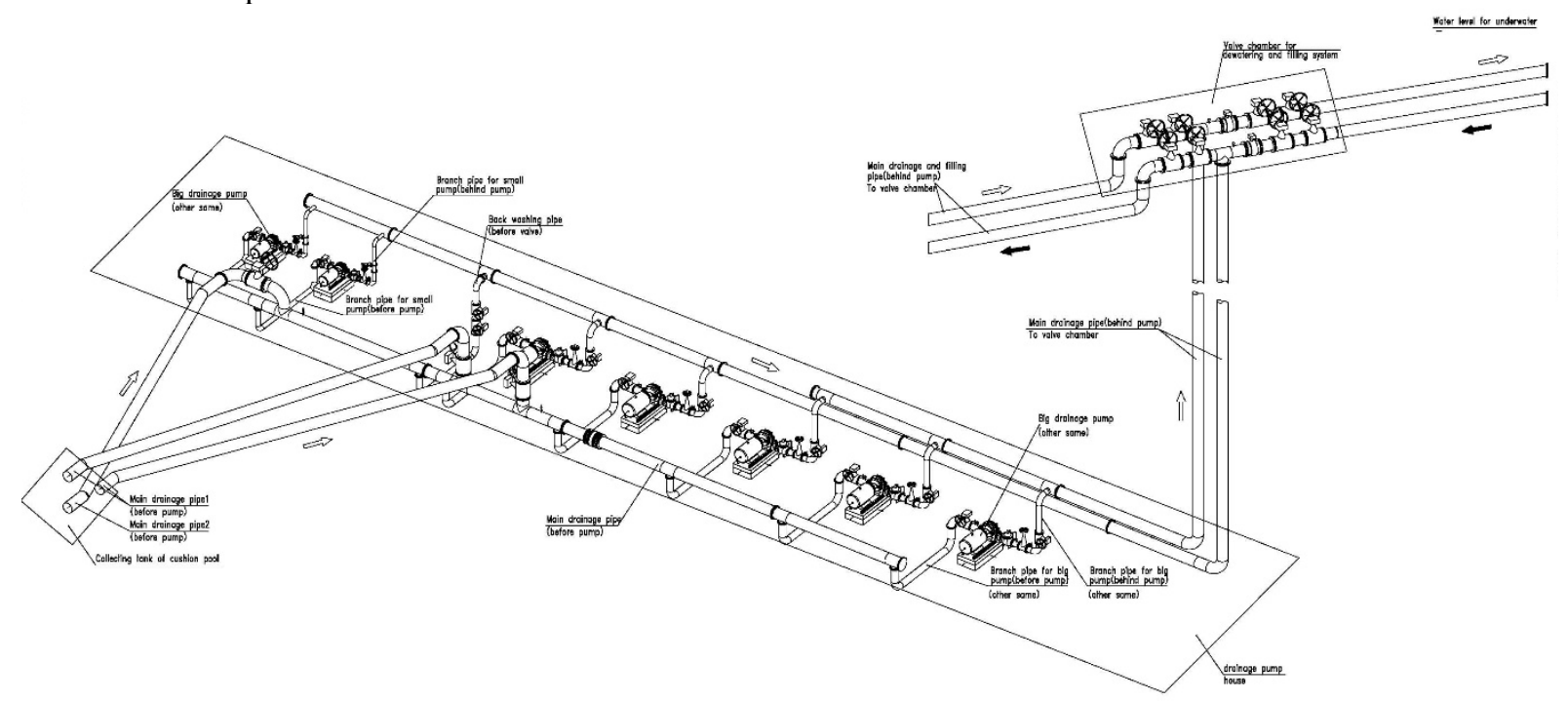

Fig.3 Three-dimensional axonometric figer of dewatering and filling system of cushion pool

\section{3 main arrangement of dewatering and filling system}

A water collecting basin is set in the area where the center line at the bottom of the inverted arch cushion pool is connected with the second-dam, and a screen is set in front of the water collecting basin to prevent rolling stones from falling into the water collecting basin, Three maintenance water intake headers with different central levels are buried in the second-dam between the water collecting basin and the second-dam pump house.

Combined with the layout of the bottom drainage corridor in the second-dam, the corridor is near the middle of the river channel as a drainage pump house. The floor elevation of the drainage pump house meets the suction requirements of the drainage pump during operation, and the layout space meets the layout requirements of water dewatering and filling pipelines and device. Combined with the layout design of drainage gallery and drainage pump house, special passages and lifting equipment are set up to meet the needs of transportation of equipment in drainage pump house and overhaul, operation and maintenance of staff.

The gravity water dewatering and filling valve chamber is arranged in the middle of the second-dam body near the water cushion pool, which is in communication with the bank slope. The layout level is below the minimum power level of the downstream river channel, which can avoid the siltation of the gravity-drainge water dewatering and filling pipeline in the upstream cushion pool and the downstream river channel. The outlet position of the pipeline is close to the side wall of the inverted arch cushion pool, which can make full use of the transition arc to dissipate energy and reduce the impact of the filled water flow on the bottom plate and bank slope of the cushion pool.

\section{4 operation mode of water cushion pool dewater and filled system}

\subsection{Cushion pool dewater and filled operation mode}

Mainly four processes are included in the operation mode of dewatering and filling system of cushion pool: automatic drainage of cushion pool, pumping and discharging clear water, backwashing of water collection basin and drainage main pipe of cushion pool, pumping and discharging sewage of cushion pool, which are as follows.

When the water level in the downstream river is low, the automatic water dewatering and filling system in dewatering and filling system of the cushion pool is used to discharge dropsy in the cushion pool to the downstream, thus the energy consumption of the system operation will be reduced. First, the indoor operation valve of gravity water dewatering and filling valve are opened, and the cushion pool is connected with gravity water dewatering and filling pipe connected with downstream river channel. By the gravity drainage function of gravity drainage 
system, all the water bodies in the cushion pool higher than the water level of the downstream river channel are discharged into the downstream river channel. The water level in the cushion pool and the water level in the downstream river channel can be judged by the flow signal change of the gravity-drainge water dewatering and filling pipe flowmeter.

When the water level of the cushion pool is basically equal to the water level of the downstream river, the operating valve should be closed to cut off the connection between the drainage pipe and the upstream cushion pool. The water inlet is opened and an overhaul water inlet main pipe is set up with higher elevation. The water body with better water quality is introduced in the cushion pool by the pump equipment pump of the pumping system composed of large and small pumps, till near the water inlet with higher elevation.

A buried overhaul water intake main pipe with lower elevation is arranged to connect the backwashing pipe and the water inlet. The overhaul water inlet main pipe and the water collecting basin are flushed by using the water pressure of the downstream tail water higher than the water level in the upstream cushion pool. After flushing, the remaining accumulated water in the cushion pool is drained by the pumping system.

\subsection{Operation Mode of Recharge Water for Maintenance of Cushion pool}

Recharge water of cushion pool is carried out after the repair of cushion pool is completed. At first, the gravitydrainge water dewatering and filling pipe is connected by opening the operation valve arranged in the gravitydrainge water dewatering and filling valve. As the water level in the downstream river channel is higher than the baseplate level in the cushion pool, the downstream water of the second-dam can be filled into the cushion pool by gravity flow through the pump house. After water filling completed, the operation valve in the gravity water dewatering and filling valve chamber will be closed. Before flood discharge in the cushion pool, the deep-hole accident gate of the dam is opened locally first, the cushion pool is filled with water to the top level of the second-dam, and then the deep-hole accident gate of the dam is fully opened to meet the flood discharge requirements.

\subsection{Maintenance and Maintenance Countermeasures}

The most difficult maintenance condition of water dewatering and filling system in cushion pool is the first isolation valve connected with the downstream river. Here, the central level of the outlet of the drainage pipeline should not lower than the tailwater level of the downstream river of the second-dam when the two units are in operating. The mouth of pipe is connected with flange and equipped with blind flange. When the drainage device, especially the first valve is overhauled, the number of two units or a few units in the power station is ordered to operating. Then, the blind flange and the flange at the outlet are connected and sealed well, so that the overhaul can be realized.

\section{5 system debugging and operation effect}

\section{1 system debugging}

The system debugging is divided into two parts, one is the gravity-drainge water dewatering and filling system debugging, and the other is the pumping and drainage system debugging. Debugging of pumping and drainage system shall be completed after filling water in cushion pool. Basing on the precise adjustment of the gate valve on the pipeline of the pumping and drainage system, the pump starts successfully and the whole pumping process is normal.

\section{2 operation effect}

After the construction of the cushion pool was completed, by the pipe connected to downstream of the second-dam water is filled to the cushion pool. In the process of water filling, the river water level downstream of the seconddam is about $595 \mathrm{~m}$, the center of gravity water dewatering and filling valve is $581.5 \mathrm{~m}$, and the using water head is about $13.5 \mathrm{~m}$. At this time, the operation valve of the gravity water dewatering and filling valve is in the fully open position, and the water flow of gravity water filling and drainage pipe impacts on the sidewall of the inverted arch cushion pool, and dissipates energy naturally, and finally collects at the bottom of the cushion pool.

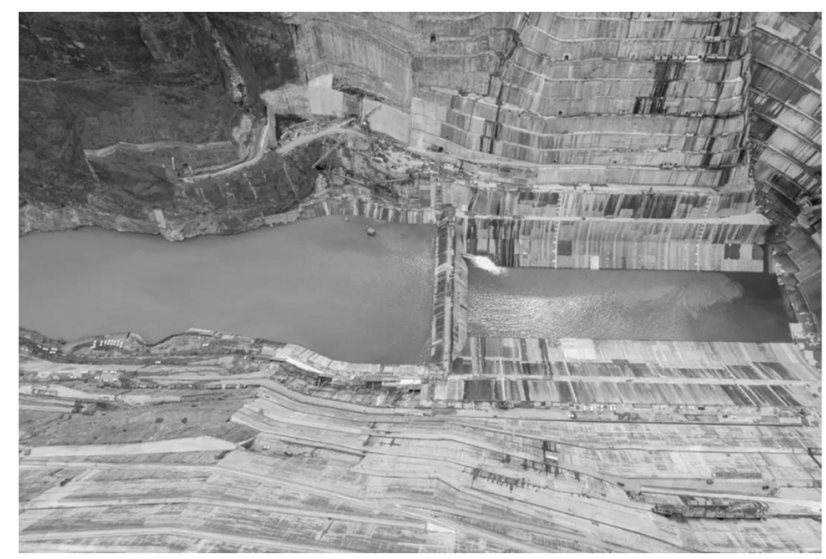

Fig.4 Effect diagram of the first water filling process in the cushion pool of the project

\subsection{Brief summary}

After the above system is adopted in engineering design and construction, a complete set of design and operation control strategies for dewatering and filling system of cushion pool is formed, which is applied well. By using this system, the water recharge of cushion pool can be completed within 4 7 days, which greatly improves the efficiency of water recharge. 


\section{Tag}

Combined with the structure of high dam and inverted arch cushion pool of energy dissipation facilities, as well as the needs of maintenance, a permanent dewatering and filling system for cushion pool is set up, which mainly includes the gravity-drainge water dewatering and filling system of cushion pool and the water pumping and drainage system of cushion pool. Completed the research on the design principle and operation mode of drainage system, and the key points and difficulties that should be paid attention to in the system research are as follows:

Setting level of gravity water dewatering and filling pipeline of cushion pool should not only consider that the water level of downstream river channel which is not be too deep so that valve for maintenance is operated, but also consider the cushion pool can meet the needs of water pressure and discharge time when refilling water, The mouth position of refilling water pipeline should be set at the place where the cushion pool is smooth and suitable for energy dissipation.

Special consideration should be given to anti-clogging measures of pipelines when overhauling the water dewatering and filling system of the cushion pool, and the pump operation head should not only meet the requirement that the water at the bottom of the cushion pool can be removed completely, but also consider the lowest limited head of the gate pressure.

\section{About the author:}

Fang Jie, male, senior engineer, master's degree, mainly engaged in hydraulic machinery design of hydropower station. E-mail: fang_j@ecidi.com

\section{References}

1. Wu linyan,pumping and drainage scheme for the first overhaul of Xiluodu dam cushion pool after flood season [J],water conservancy construction, 2015, (12); 207 208.

2. Junfeng Gao,Study on the first drainage and maintenance process of Xiluodu cushion pool [J],Urban Architecture, 379,382 .

3. Wang Youwei,Analysis on operational risk of cushion pool in Xiluodu Hydropower Station [J],Dam and Safety, 2013, (2); 12 14,22 .

4. Wang Fenghui,Design and safe operation management of cushion pool of Ertan Hydropower Station [J],Dam and Safety, 2006, (5), 1 4 .

5. Duan Xufang,Design summary of $6.3 / 0.4 \mathrm{kV}$ drainage project in cushion pool of Ertan Hydropower Station [J],Mechanical and Electrical Equipment, 2009, (1), 37 40 .

6. Wan Xiongwei, Xu Ying, Xiao Hao, et al,Study on anti-abrasion repair of cushion pool of Ertan Hydropower Station [J], Water Resources and Hydropower Technology, 2013,44 (9), 96 99 .

7. Li Xinyao,Study on slope protection structure type of cushion pool in wudongde hydropower station [J],Water Resources and Hydropower Technology, 2017,48 (11), 26 30 .

8. Hu Qingyi, Liao Renqiang, Guo Yanyang, etc,Study on flood discharge and energy dissipation design in wudongde hydropower station [J],People's Changjiang River, 2014,45 (2); 21 23 .

9. Leng Dongsheng, Min Yang, Ma Bin, et al,Study on vibration characteristics of cushion pool floor based on Jinping I prototype observation [J],South-to-North Water Transfer Project, 2016,14 (6), 105 110 .

10. Zhou Zhong, Tang Zhongmin,General layout of Jinping I Hydropower Station [J],People's Changjiang River, 2009,40 (18); 18 20 .

11. Li Manlin, Song Lingli,Design of energy dissipation and scour prevention for Jinping I Hydropower Station [J],Design of Hydropower Station, 2010,26 (3); 17 20 .

12. Zhang Yinsheng, Shao Zengfu, Treatment of concrete defects in Goupitan Hydropower Station after water overflow [J],Guizhou Hydropower, 2010,24(4), 38 42.

13. Fan Shuangzhu, Qian Qili,Application of Epoxy Grouting in Concrete Crack Treatment of Cushion pool of Goupitan Hydropower Station [J],Water Resources and Hydropower Technology, 2009,40 (6), 25 29.

14. Xiang Guanghong, Jin Lei, Ban Hongyan, etc,Flood discharge and energy dissipation design of Goupitan Hydropower Station [J],People's Changjiang River, 2006,37 (3); 42 44.

15. Yang Cunlong, Ren Zongshe, Sun Yujun, etc,Optimal design of inverted arch cushion pool of Laxiwa Hydropower Station [J],Hydropower, 2007,33 (11); 7 10 .

16. Chen Liang, Lu Liang, Zhang Ying,Research and application of inverted arch cushion pool structure in Laxiwa Hydropower Station [J],Journal of Water Resources and Architectural Engineering, 2013,11 (2); 196 199.

17. Yao Shuanxi, Wang Ya 'e, Du Shengzong, etc,Application and research results of inverted arch cushion pool in Laxiwat high arch dam junction [J],Northwest Hydropower, 2010, (1); 23 27 .

18. Chien Sun, Li Yuzhu, Yu Changzhao,Experimental study on cushion pool with slope protection without bottom protection in Xiaowan Project [J],Water Resources and Hydropower Technology, 2001,32 (5), 52 56.

19. Chen Jie, Zhou Sheng, Sun Shuangke,Study on optimization of flood discharge and energy dissipation layout of Xiaowan Hydropower Station [J],Hydropower, 2001, (10); 38 41 .

20. East China Survey \& Design Institute Co., Ltd,Feasibility Study Report of Baihetan Hydropower Station on Jinsha River [R],Hangzhou: East China Survey \& Design Institute Co., Ltd., 2016. 